\title{
Chronic Obstructive Airways Diseases: Where Are We Now?
}

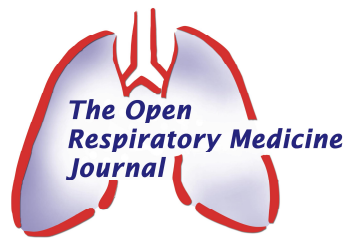

\author{
Jordan Minov ${ }^{\S}$ and Saso Stoleski ${ }^{*} \S$
}

\begin{abstract}
Center for Respiratory Functional Diagnostics, Institute for Occupational Health, WHO Collaborating Center and $G A^{2}$ LEN Collaborating Center, II Makedonska Brigada 43, 1000 Skopje, R. Macedonia
\end{abstract}

Chronic obstructive airway diseases (asthma, chronic obstructive pulmonary disease, bronchiectasis, and cystic fibrosis) are chronic inflammatory disorders characterized by airflow obstruction and subsequent airflow limitation. Airflow limitation can be present in different severities and clinical expressions.

These diseases, especially asthma and chronic obstructive pulmonary disease (COPD), cause considerable morbidity and mortality and consume substantial and increasing health care resources, this have become important global public health problem in the last decades. There is evidence that asthma affects $1-18 \%$ of the population in different countries [1]. In addition, COPD is one of the most important causes of death in most countries, i.e. it is estimated that COPD will become the third leading cause of death worldwide by 2020 [2].

Despite increasing knowledge about the mechanisms, patophysiology, diagnostics, and treatment of these diseases, the problem of chronic obstructive airway disease remains far from being solved. From the doctors' point of view there are still many controversies in all aspects of these diseases. From the patients' point of view there are still many unmet needs, as well.

The best illustration of this maybe is still an ongoing debate between the Dutch hypothesis and the British hypothesis. In 1961, Orie et al. [3] put forward the hypothesis that various forms of airway obstruction, such as asthma, chronic bronchitis and emphysema, should not be considered as separated diseases but rather as different expressions of one disease entity: chronic non-specific lung disease (CNSLD). In 1969, Fletcher et al. [4] suggested the name Dutch hypothesis. The principle of the Dutch hypothesis is that various forms of obstructive airway disease overlap clinical features, and suggest using a number of defining characteristics (symptoms and signs, allergy,

\footnotetext{
*Address correspondence to this author at the Center for Respiratory Functional Diagnostics, Institute for Occupational Health, WHO Collaborating Center and $\mathrm{GA}^{2}$ LEN Collaborating Center, II Makedonska Brigada 43, 1000 Skopje, R. Macedonia; Tel: +389 71314 435;

Fax: +389 22621 428; E-mail: sstoleski@yahoo.com
}

bronchial hyperresponsiveness, etc.) to describe the individual patient with CNSLD, rather than trying to categorize a patient with specific disease label [5]. On the contrary, the British hypothesis [6] suggests that asthma and COPD are distinct entities generated by different mechanisms, i.e. there are marked differences in the patterns of the underlying inflammation, cellular mechanisms, inflammatory mediators, and response to therapy between asthma and COPD. This issue remains hotly debated particularly as we are entering a new era of molecular phenotyping and targeted biologic therapies. Results from actual study based on biological clustering of asthma and COPD indicate that sputum cytokine profiling can determine distinct and overlapping groups of patients with asthma and COPD, supporting both the Dutch and British hypothesis of airway disease [7]. Furthermore, from the clinical point of view, distinguishing asthma from COPD can be problematic, particularly in smokers and older adults. The Asthma COPD overlap syndrome (ACOS) is a clinical entity characterized by persistent airflow limitation with several features usually associated with asthma and several features usually associated with COPD. Such consensus-based description of the ACOS is intended to stimulate further study of the character and treatments for this common clinical problem [1].

What can we say? There is no doubt that the knowledge about chronic obstructive airway diseases is growing and it is a reflection of the progress that has been made. However, there is always a need of further investigations of different aspects of these diseases. In addition, every study represents a small piece of knowledge that participates in the whole knowledge of this field of respiratory medicine.

\section{REFERENCES}

[1] Global Initiative for Asthma: Revised 2014. Available at: www.ginasthma.com [Assessed February 16, 2015].

[2] Global Strategy for the Diagnosis, Management, and Prevention of Chronic Obstructive Pulmonary Disease: 2014 Update. Available at: http://www.goldcopd.org/ [Assessed February 16, 2015].

[3] Orie NGM, Sluiter HJ, De Vries K, Tammeling GJ, Witkop J. The host factors in bronchitis. In: Orie NGM, Sluiter HJ, Eds. Bronchitis. Assen: Royal van Gorcum 1961.

${ }^{\S}$ Guest Editors. 
[4] Fletcher C, Peto R, Tinker C, Speizer FE. The natural history of chronic bronchitis and emphysema. London: Oxford University Press 1976.

[5] Sluiter HJ, Koeter GH, De Monchy JGR, Postma DS, De Vries K, Orie NGM. The Dutch hypothesis (chronic non-specific lung disease) revisited. Eur Respir J 1991; 4: 479-89.
[6] Barnes PJ. Against the Dutch hypothesis: asthma and chronic obstructive pulmonary disease are distinct diseases. Am J Respir Crit Care Med 2006; 174: 240-3.

[7] Ghebre MA, Bafadhel M, Desai D, et al. Biological clustering supports both "Dutch" and "British" hypothesis of asthma and chronic obstructive pulmonary disease. J Allergy Clin Immunol 2015; 135: 63-72.

(C) Minov and Stoleski.; Licensee Bentham Open.

This is an open access article licensed under the terms of the Creative Commons Attribution Non-Commercial License (http://creativecommons.org/licenses/by-nc/3.0/) which permits unrestricted, non-commercial use, distribution and reproduction in any medium, provided the work is properly cited. 